\title{
Human leukocyte antigen mismatching and survival after lung transplantation in adult and pediatric patients with cystic fibrosis
}

\author{
Don Hayes, Jr, MD, MS, ${ }^{\text {a,b,c }}$ Jeffery J. Auletta, MD, ${ }^{\text {a,de,f }}$ Bryan A. Whitson, MD, PhD, ${ }^{\mathrm{g}}$ \\ Sylvester M. Black, MD, PhD, ${ }^{\mathrm{g}}$ Stephen Kirkby, MD, ${ }^{\mathrm{a}, \mathrm{b}, \mathrm{c}}$ Joseph D. Tobias, MD, ${ }^{\mathrm{h}, \mathrm{i}}$ and \\ Heidi M. Mansour, $\mathrm{PhD}^{\mathrm{j}}$
}

\begin{abstract}
Introduction: The influence of human leukocyte antigen (HLA) mismatching on survival in adult and pediatric patients with cystic fibrosis $(\mathrm{CF})$ after lung transplantation (LTx) is unknown.

Methods: The United Network for Organ Sharing database was queried from 1987 to 2013 to determine the influence of HLA mismatching on survival in adult and pediatric CF LTx recipients by assessing the association of HLA mismatching with survival in first-time adult (aged $\geq 18$ years) and pediatric (aged $<18$ years) recipients.
\end{abstract}

Results: Of 3149 adult and 489 pediatric patients with CF, 3145 and 489 were used for univariate Cox analysis, 2687 and 363 for Kaplan-Meier survival analysis, and 2073 and 257 for multivariate Cox analysis, respectively. Univariate analyses in adult and pediatric patients with CF demonstrated conflicting associations between HLA mismatching and survival (adult hazard ratio [HR], $1.0 ; 95 \%$ confidence interval $[\mathrm{CI}], 0.97-1.1 ; P=.45$ vs pediatric HR, 0.87 ; $95 \% \mathrm{CI}, 0.77-0.99 ; P=.032)$. Multivariate Cox models including both pediatric and adult patients confirmed that HLA mismatching had an initially protective effect at young ages $(\mathrm{HR}, 0.85 ; 95 \% \mathrm{CI}, 0.73-0.99 ; P=.044)$ and that this protective effect diminished at older ages and was no longer associated with survival at $P<.05$ beyond age 10 years.

Conclusions: HLA mismatching has significantly different implications for survival after LTx in adult compared with pediatric patients with CF. (J Thorac Cardiovasc Surg 2016;151:549-57)

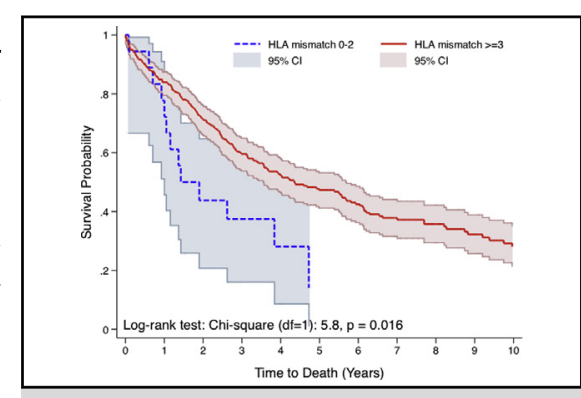

Kaplan-Meier survival functions for children with cystic fibrosis by human leukocyte antigen mismatch.

\section{Central Message}

Human leukocyte antigen mismatching has a protective effect in young patients with cystic fibrosis with loss of this effect beyond age 10 years.

Perspective

The present study provides some insight into what appears to be immunologic distinctions according to age in adult and pediatric lung transplant recipients with cystic fibrosis. Further research is needed to better define the influence of humoral immunity on age-related survival disparities in this patient population.

See Editorial Commentary page 558

See Editorial page 315 .
Lung transplantation (LTx) has become a well-established treatment option for both adult and pediatric patients who have cystic fibrosis (CF) with advanced lung disease. ${ }^{1,2} \mathrm{~A}$

\footnotetext{
From the Departments of ${ }^{\mathrm{a}}$ Pediatrics, ${ }^{\mathrm{b}}$ Internal Medicine, ${ }^{\mathrm{g}}$ Surgery, and ${ }^{\mathrm{h}}$ Anesthesiology, The Ohio State University College of Medicine, Columbus, Ohio; ${ }^{\mathrm{c} S e c t i o n}$ of Pulmonary Medicine, ${ }^{\mathrm{d}}$ Host Defense Program, ${ }^{\mathrm{e}} \mathrm{Section}$ of Hematology/Oncology and Bone Marrow Transplantation, ${ }^{\mathrm{f}}$ Section of Infectious Diseases, and ${ }^{\mathrm{i}} \mathrm{De}-$ partment of Anesthesiology and Pain Medicine, Nationwide Children's Hospital, Columbus, Ohio; and ${ }^{\mathrm{j}}$ Skaggs Pharmaceutical Sciences Center, The University of Arizona College of Pharmacy, Tucson, Ariz.

Received for publication Feb 26, 2015; revisions received Aug 3, 2015; accepted for publication Aug 10, 2015; available ahead of print Sept 20, 2015.

Address for reprints: Don Hayes, Jr, MD, MS, The Ohio State University, Nationwide Children's Hospital, 700 Children's Dr, Columbus, OH 43205 (E-mail: hayes. 705@osu.edu).

$0022-5223 / \$ 36.00$

Copyright $(2016$ by The American Association for Thoracic Surgery

http://dx.doi.org/10.1016/j.jtcvs.2015.08.022
}

recent analysis of the United Network for Organ Sharing (UNOS) registry examining patients between 2005 and 2009 after implementation of the lung allocation score (LAS) demonstrated a survival benefit for adults with $\mathrm{CF}^{3}$ However, the long-term benefit of LTx in children with CF has been widely debated and remains controversial. $^{4-6}$ In 2007, Liou and colleagues ${ }^{4}$ published that 5 of 514 wait-listed patients had improved survival through proportional-hazards modeling of wait-listed pediatric

Scanning this QR code will take you to supplemental tables for this article. 


$$
\begin{aligned}
& \text { Abbreviations and Acronyms } \\
& \text { AMR }=\text { antibody-mediated rejection } \\
& \text { BOS }=\text { bronchiolitis obliterans syndrome } \\
& \text { CF }=\text { cystic fibrosis } \\
& \text { DSA }=\text { donor-specific anti-HLA antibody } \\
& \text { HLA }=\text { human leukocyte antigen } \\
& \text { LAS }=\text { lung allocation score } \\
& \text { LTx }=\text { Lung transplantation } \\
& \text { UNOS }=\text { United Network for Organ Sharing }
\end{aligned}
$$

patients with CF who underwent LTx between 1992 and 2002. ${ }^{4}$ Subsequent criticisms of these findings included the use of registry data not being updated at the time of LTx with covariates being acquired up to 2 years before listing, which equated to $\geq 3$ years before LTx, and the use of a cohort of patients before the implementation of the LAS system in the United States. ${ }^{5,6}$

Using piecewise-constant hazard rate, our group recently reported that the hazard of post-LTx mortality in CF is highest between ages 16 and 20 years, but this risk declined at later attained ages, controlling for age at LTx and other donor, recipient, and transplant characteristics. ${ }^{7}$ Due to the study design of that analysis, we could not determine any factors contributing to the death of adolescent CF patients after LTx. Given that the age at time of LTx in adolescents with CF negatively influenced survival but not for adult CF patients, ${ }^{7}$ we sought to investigate immunologic differences as potential factors contributing to the disparities seen in the adult and pediatric $\mathrm{CF}$ patient populations. With no data available regarding human leukocyte antigen (HLA) mismatching in CF patients receiving LTx, we used the UNOS Registry to analyze HLA mismatching in both adult and pediatric CF patient groups. We hypothesized that HLA mismatching negatively influences long-term outcomes of LTx in both CF age groups.

\section{METHODS \\ Data Collection}

We retrospectively evaluated data from patients who were registered in the Organ Procurement and Transplant Network Standard Transplant Analysis and Research Database ${ }^{8}$ administered by UNOS. The study was approved by The Ohio State University Wexner Medical Center Institutional Review Board with a waiver of the need for individual consent (IRB\#2012H0306). The UNOS/Organ Procurement and Transplant Network thoracic database was queried for all patients with CF between October 1987 and September 2013 who received first-time, cadaveric LTx with known transplant date and were not duplicate entries. A total of 3149 adult patients with $\mathrm{CF}$ (aged $\geq 18$ years) and 489 pediatric patients with $\mathrm{CF}$ (younger than age 18 years) were included in the analysis.

\section{Statistical Methods}

All analyses were performed using Stata/MP, version 13.1 (StataCorp LP, College Station, Tex). Descriptive statistics for continuous variables are presented as means and standard deviations; and descriptive statistics for categorical variables are presented as proportions. Survival analysis was performed on time from LTx to the date of death. There were 4 adult patients with $\mathrm{CF}$ with unknown time spent at risk, and these were excluded from the survival analysis. Eighteen patients had 0 days at risk, of whom 17 died due to the following causes: intraoperative hemorrhage (7 cases), infection (4 cases), and other causes ( 6 cases). Patients with 0 days at risk were assigned an arbitrarily small duration at risk $<1$ day to be retained in the survival analysis. Whereas the present analysis focused on patient survival, hospitalization due to infection, and the development of posttransplant bronchiolitis obliterans syndrome (BOS) within a year of LTx were also described as secondary outcomes.

The main covariates of interest were HLA mismatch level (dichotomized as $\geq 3$ vs 0 - 2 in descriptive and Kaplan-Meier analyses, but treated as continuous in the regression analysis) at time of listing for LTx with a total of 6 being possible with the loci, including A, B, and DR. The level of mismatch used to illustrate differences in survival curves and patient characteristics was arbitrarily chosen. Cox proportional hazards analysis related HLA mismatch to survival after LTx separately in adults and children, and in the combined sample with continuous age as a moderator of this relationship. Multivariate Cox proportional hazards analysis adjusted for recipient characteristics, donor characteristics, and transplant characteristics. The sample for the multivariate analysis was constructed from cases with complete data on all covariates. Six-minute walk distance was not included in the multivariate models due to the high proportion of missing data and the fact that this variable was only collected from 2001 to 2006 . The final LAS was only available for patients transplanted in May 2005 or later, and this variable was only considered as a covariate in separate models fitted to the 2005 to 2013 subsample.

\section{RESULTS \\ Study Population}

Tables 1 and 2 summarize demographic information and characteristics of the adult and pediatric patients using the HLA mismatch $\geq 3$ threshold to illustrate differences across HLA mismatch level. In the adult CF population (Table 1), the 2 groups divided by HLA mismatch level were similar in recipient and donor sex, recipient race, and other recipient characteristics (eg, infection requiring intravenous drug therapy during the 2 weeks before LTx, age, creatinine, body mass index, pulmonary function, functional capacity, and final LAS) and transplant characteristics (transplant year and graft ischemic time). However, the HLA $\geq 3$ mismatch group had significantly more adult $\mathrm{CF}$ patients who received allografts from nonwhite donors. A comparison across the same threshold of HLA mismatch in the pediatric CF population (Table 2) also revealed similarity across the same characteristics, with the exception of infection before LTx, which was more common in the HLA $\geq 3$ mismatch group.

In the adult subsample, 472 patients $(22 \%)$ were hospitalized for infection within a year of LTx, whereas $59(2 \%)$ developed BOS within the same time span. In the pediatric subsample, there were 84 patients $(22 \%)$ hospitalized for infection within 1 year, and 18 (4\%) who developed BOS within 1 year of LTx. A comparison of continuous HLA mismatch level between patients who were not hospitalized for infection and those who were not found no significant differences among either children $(P=.78)$ or adults $(P=.99)$. Likewise, patients who developed BOS were not distinguished from patients who did not develop BOS in their level of HLA mismatch among either children $(P=.90)$ or adults $(P=.50)$. These 
TABLE 1. Patient demographic information and characteristics of adults with cystic fibrosis according to human leukocyte antigen (HLA) mismatch $\geq 3$ versus 0 to 2

\begin{tabular}{|c|c|c|c|c|c|c|c|c|c|}
\hline \multirow[b]{2}{*}{ Variable } & \multirow{2}{*}{$\begin{array}{c}\text { Missing } \\
\text { data }\end{array}$} & \multicolumn{2}{|c|}{ All $*(n=3149)$} & \multicolumn{2}{|c|}{$\begin{array}{c}\text { HLA } \geq 3 \\
(n=2599)\end{array}$} & \multicolumn{2}{|c|}{$\begin{array}{c}\text { HLA 0-2 } \\
(n=91)\end{array}$} & \multicolumn{2}{|c|}{$P$ value } \\
\hline & & n $(\%)$ & Mean \pm SD & n $(\%)$ & Mean \pm SD & n $(\%)$ & Mean \pm SD & $t$ test & $\chi^{2}$ \\
\hline Male recipient & 0 & $1716(54)$ & - & $1395(54)$ & - & $56(62)$ & - & - & .14 \\
\hline Male donor & 0 & $1813(58)$ & - & $1505(58)$ & - & $50(55)$ & - & - & .57 \\
\hline Race of recipient & 0 & - & - & - & - & - & - & - & .54 \\
\hline White & - & 3034 (96) & - & 2505 (96) & - & $88(97)$ & - & - & - \\
\hline Black & - & $36(1.1)$ & - & $29(1.1)$ & - & 0 & - & - & - \\
\hline Other & - & $79(2.5)$ & - & $65(2.5)$ & - & $3(3.3)$ & - & - & - \\
\hline Race of donor & 0 & - & - & - & - & - & - & - & $<.001$ \\
\hline White & - & $2120(67)$ & - & $1721(66)$ & - & $80(88)$ & - & - & - \\
\hline Black & - & $517(16)$ & - & 448 (17) & - & $5(5.5)$ & - & - & - \\
\hline Other & - & $512(16)$ & - & $430(17)$ & - & $6(6.6)$ & - & - & - \\
\hline Infection before lung transplant & 384 & $1238(45)$ & - & $1019(45)$ & - & $29(37)$ & - & - & .15 \\
\hline Age (y) & 0 & - & $31(9.1)$ & - & $31(9.2)$ & - & $32(9.4)$ & .16 & - \\
\hline Transplant year & 0 & - & $2004(6.2)$ & - & $2004(6.2)$ & - & $2003(6.1)$ & .45 & - \\
\hline Creatinine $(\mathrm{mg} / \mathrm{dL})$ & 248 & - & $0.78(0.55)$ & - & $0.78(0.52)$ & - & $0.81(0.33)$ & .58 & - \\
\hline Body mass index & 3 & - & $19(2.9)$ & - & $19(2.9)$ & - & $19(2.8)$ & .93 & - \\
\hline Ischemic time (h) & 251 & - & $5.8(1.7)$ & - & $5.8(1.7)$ & - & $5.9(1.6)$ & .58 & - \\
\hline Forced expiratory volume in $1 \mathrm{~s}(\%$ predicted $)$ & 261 & - & $26(14)$ & - & $26(13)$ & - & $25(15)$ & .72 & - \\
\hline Forced vital capacity ( $\%$ predicted $)$ & 252 & - & $41(14)$ & - & $41(14)$ & - & $40(14)$ & .73 & - \\
\hline 6-Mintue walk test $(100 \mathrm{ft})$ & 2860 & - & $10(5.3)$ & - & $10(5.2)$ & - & $11(3.0)$ & .68 & - \\
\hline Lung allocation score & 1621 & - & $47(16)$ & - & $47(16)$ & - & $47(16)$ & .90 & - \\
\hline HLA mismatch & 459 & - & $4.6(1.1)$ & - & $4.7(0.95)$ & - & $1.7(0.53)$ & $<.001$ & - \\
\hline
\end{tabular}

$H L A$, Human leukocyte antigen; $S D$, standard deviation. *A total of 2690 cases had data on HLA mismatch.

secondary outcomes appeared to be unrelated to a continuous measure of HLA mismatch in this study.

\section{Univariate and Kaplan-Meier Survival Analysis}

The univariate Cox proportional hazards analysis revealed conflicting results for adult compared with pediatric CF patients (Tables 3 and 4 ). In patients aged $\geq 18$ years, a continuous measure of HLA mismatch was not statistically significantly associated with survival, with a hazard ratio (HR) of $1.0 ; 95 \%$ confidence interval (CI) of 0.97 to 1.1 , and $P=.045$ (Table 3). Among patients aged $<18$ years, on the other hand, the hazard of mortality was reduced for patients with higher levels of HLA mismatch (HR, 0.87; 95\% CI, 0.77-0.99; $P=.032$ ) (Table 4). Adding polynomial (eg, quadratic) transformations of HLA mismatch level did not indicate that the relationship between HLA mismatch and survival was nonlinear among either adults or children (results available upon request). Kaplan-Meier survival function curves comparing HLA $\geq 3$ and 0 to 2 mismatch groups in the adult CF population (Figure 1) and pediatric CF population (Figure 2) found similarly conflicting results, with log-rank tests indicating an inverse association between HLA mismatch and mortality hazard among children, but not among adults. Number of patients at risk by HLA mismatch level and year since transplant for both adult and pediatric groups are outlined in Tables E1 and E2.
Several variables were found to be significant in the univariate Cox models for the adult patients with $\mathrm{CF}$ (Table 3 ). Black donor race, among adults receiving a transplant in May 2005 or later, higher final LAS, were significantly associated with increased mortality hazard. Meanwhile, several covariates were protective against death. Older age, higher pulmonary function (forced vital capacity and forced expiratory volume in 1 second), and functional capacity (6-minute walk distance in hundreds of feet) were protective with a decrease in the HR for mortality. A more recent LTx was associated with a lower hazard of death among adults in the univariate analysis. No variables other than HLA mismatch level were significantly associated with mortality in the univariate Cox models for the pediatric patients with CF (Table 4).

\section{Multivariate Survival Analysis}

Adjusting for confounders in the subsample of adult patients with $\mathrm{CF}$, multivariate Cox proportional hazard models identified no relation between HLA mismatch level (as a continuous variable) and mortality hazard (HR, 1.0; $95 \%$ CI, $0.95-1.1 ; P=.68$ ) (Table 5). Restricting the analysis to transplants performed in May 2005 or later and controlling for final LAS did not change this finding (Table 5, Model 2), whereas LAS itself was not significantly related to the outcome net of the other covariates. Covariates that remained significantly related to mortality among adult 
TABLE 2. Patient demographic information and characteristics of children with cystic fibrosis according to human leukocyte antigen (HLA) mismatch $\geq 3$ versus 0 to 2

\begin{tabular}{|c|c|c|c|c|c|c|c|c|c|}
\hline \multirow[b]{2}{*}{ Variable } & \multirow{2}{*}{$\begin{array}{c}\text { Missing } \\
\text { data }\end{array}$} & \multicolumn{2}{|c|}{ All $*(n=489)$} & \multicolumn{2}{|c|}{$\begin{array}{l}\text { HLA } \geq 3 \\
(n=342)\end{array}$} & \multicolumn{2}{|c|}{$\begin{array}{l}\text { HLA 0-2 } \\
(n=21)\end{array}$} & \multicolumn{2}{|c|}{$P$ value } \\
\hline & & n $(\%)$ & Mean \pm SD & n $(\%)$ & Mean \pm SD & n $(\%)$ & Mean \pm SD & $t$ test & $\chi^{2}$ \\
\hline Male recipient & 0 & $191(39)$ & - & $132(39)$ & - & 4 (19) & - & - & .072 \\
\hline Male donor & 0 & $248(51)$ & - & $187(55)$ & - & $9(43)$ & - & - & .29 \\
\hline Race of recipient & 0 & - & - & - & - & - & - & - & .77 \\
\hline White & - & 427 (87) & - & 306 (89) & - & $19(90)$ & - & - & - \\
\hline Black & - & $11(2.3)$ & - & $8(2.3)$ & - & 0 & - & - & - \\
\hline Other & - & $51(10.4)$ & - & $28(8.2)$ & - & $2(9.5)$ & - & - & - \\
\hline Race of donor & 0 & - & - & - & - & - & - & - & .080 \\
\hline White & - & $321(66)$ & - & $223(65)$ & - & $18(86)$ & - & - & - \\
\hline Black & - & $82(17)$ & - & $60(18)$ & - & 0 & - & - & - \\
\hline Other & - & $86(18)$ & - & $59(17)$ & - & $3(14)$ & - & - & - \\
\hline Infection before lung transplant & 63 & $256(60)$ & - & $171(59)$ & - & $5(31)$ & - & - & .029 \\
\hline Age (y) & 0 & - & $14(3.1)$ & - & $14(3.0)$ & - & $15(2.3)$ & .13 & - \\
\hline Transplant year & 0 & - & $2003(6.2)$ & - & $2002(6.2)$ & - & $2001(7.2)$ & .68 & - \\
\hline Creatinine $(\mathrm{mg} / \mathrm{dL})$ & 67 & - & $0.61(1.1)$ & - & $0.62(1.2)$ & - & $0.47(0.18)$ & .62 & - \\
\hline Body mass index & 15 & - & $17(2.8)$ & - & $17(2.8)$ & - & $18(3.0)$ & .054 & - \\
\hline Ischemic time (h) & 28 & - & $5.4(1.4)$ & - & $5.4(1.5)$ & - & $5.3(1.4)$ & .67 & - \\
\hline Forced expiratory volume in $1 \mathrm{~s}(\%$ predicted $)$ & 65 & - & $30(14)$ & - & $30(15)$ & - & $33(19)$ & .35 & - \\
\hline Forced vital capacity ( $\%$ predicted) & 62 & - & $42(15)$ & - & $43(15)$ & - & $44(15)$ & .68 & - \\
\hline 6-Minute walk test (100 ft) & 437 & - & $11(5.1)$ & - & $10(4.6)$ & - & $16(7.2)$ & .12 & - \\
\hline Lung allocation score & 281 & - & $41(16)$ & - & $43(17)$ & - & $41(7.5)$ & .79 & - \\
\hline HLA mismatch & 126 & - & $4.6(1.1)$ & - & $4.7(0.94)$ & - & $1.9(0.44)$ & $<.001$ & - \\
\hline
\end{tabular}

$H L A$, Human leukocyte antigen; $S D$, standard deviation. *A total of 363 cases had data on HLA mismatch.

patients included black donor race being associated with greater hazard of death, and greater forced expiratory volume in 1 second and older age reducing the hazard. Adding polynomial transformations of age (eg, a quadratic term) to the model did not alter the main findings for HLA mismatch (results available upon request).

After adjusting for all confounders among pediatric patients with $\mathrm{CF}$, the multivariate Cox proportional hazard model showed that the continuous measure of HLA mismatch fell short of attaining a statistically significant association with mortality, despite retaining the same magnitude (HR, 0.87; 95\% CI, 0.73-1.0; $P=.093$ ) (Table 6, Model 1). Nevertheless, in the subsample of pediatric patients with CF transplanted in May 2005 or later, and with the addition of a control for final LAS, HLA mismatch remained inversely associated with mortality hazard in the multivariate analysis (HR, 0.71; 95\% CI, 0.54-0.93; $P=.015$ ) (Table 6, Model 2). Covariates significantly associated with greater mortality hazard among all pediatric patients with CF included black recipient race and older age. In comparison, donor race other than black or white was associated with lower mortality hazard.

Conflicting results on the relationship between HLA mismatch level and mortality hazard in the adult and pediatric subsamples suggested that the HR of HLA mismatch was dependent on age at transplantation. Two multivariate Cox proportional hazards models interacting continuous HLA mismatch with continuous age were fitted in Table 7. Model 3 includes the main effects of HLA mismatch and age, and their interaction, but no additional covariates. This model suggests that at age 0 years, HLA mismatch is inversely related to mortality hazard (HR, $0.87 ; 95 \% \mathrm{CI}, 0.77-0.99$; $P=.030$ ), but this HR increases as age (scaled by a factor of 10) increases, with the interaction HR being statistically significant and $>1$ (HR, 1.1; 95\% CI, 1.0-1.1; $P=.023$ ). Thus, Model 3 implies that at age 10 years, the relationship between HLA mismatch and mortality hazard diminishes, but remains statistically significant (HR, 0.90; 95\% CI, $0.81-0.99 ; P=.036$ ). This pattern is confirmed after adjusting for all covariates in Model 4, with the interaction between HLA mismatch and age remaining significant and in the same direction as in the unadjusted model (HR, 1.1; 95\% CI, 1.0-1.1; $P=.038$ ).

Both Model 3 and Model 4 imply that at some age, the HR of HLA mismatch will cease to be significantly different from 1. The age threshold below which HLA mismatch was inversely related to mortality hazard at $P<.05$ was 15 years in Model 3 and 10 years in the fully adjusted Model 4. Beyond these respective ages, a continuous measure of HLA mismatch was not significantly related to mortality hazard in the corresponding model. Whereas age was entered as a linear term in Table 7, adding polynomial (eg, quadratic) transformations of age to Models 3 and 4 and interacting the quadratic age terms 
TABLE 3. Univariate Cox survival analysis of adults with cystic fibrosis $(\mathbf{n}=\mathbf{3 1 4 5})$

\begin{tabular}{lcccc}
\hline \multicolumn{1}{c}{ Variable } & n & $\begin{array}{c}\text { Hazard } \\
\text { ratio }\end{array}$ & $\begin{array}{c}\text { 95\% } \\
\text { Confidence } \\
\text { interval }\end{array}$ & $\begin{array}{c}\boldsymbol{P} \\
\text { value }\end{array}$ \\
\hline $\begin{array}{l}\text { Human leukocyte antigen } \\
\text { mismatch }\end{array}$ & 2687 & 1.0 & $0.97-1.1$ & .45 \\
Male recipient & 3145 & 1.0 & $0.94-1.1$ & .49 \\
Male donor & 3145 & 1.0 & $0.90-1.1$ & .95 \\
Race of recipient & 3145 & & & \\
$\quad$ White & & ref & & \\
$\quad$ Black & & 1.2 & $0.76-1.8$ & .47 \\
$\quad$ Other & & 0.82 & $0.58-1.2$ & .28 \\
Race of donor & 3145 & & & \\
$\quad$ White & & ref & & \\
$\quad$ Black & & 1.2 & $1.0-1.4$ & .010 \\
$\quad$ Other & & 1.1 & $0.93-1.2$ & .37 \\
Infection before lung transplant & 2765 & 1.2 & $1.0-1.3$ & .009 \\
Age (y) & 3145 & 0.98 & $0.97-0.98$ & $<.001$ \\
Transplant year & 3145 & 0.98 & $0.97-0.98$ & $<.001$ \\
Creatinine (mg/dL) & 2901 & 1.1 & $0.97-1.2$ & .16 \\
Body mass index & 3142 & 0.98 & $0.96-1.0$ & .082 \\
Ischemic time (h) & 2898 & 0.97 & $0.94-1.0$ & .054 \\
Forced expiratory volume & 2888 & 0.99 & $0.99-1.0$ & .022 \\
$\quad$ in 1 s (\% predicted) & & & & \\
Forced vital capacity & 2897 & 0.99 & $0.99-1.0$ & .016 \\
$\quad$ (\% predicted) & & & & \\
6-Minute walk test (100 ft) & 289 & 0.96 & $0.93-0.99$ & .012 \\
Lung allocation score & 1524 & 1.0 & $1.0-1.0$ & .001 \\
\hline ref, Reference category. & & & &
\end{tabular}

with HLA mismatch did not reveal statistically significant interactions between the square of age and HLA mismatch. This suggested that was the log hazard ratio of HLA mismatch was linearly dependent on age at transplantation (results available upon request).

\section{DISCUSSION}

The majority of the medical literature on the influence of HLA mismatching on clinical outcomes after LTx are limited to single-center observations. Although results vary, the generally accepted consensus is that HLA mismatching is detrimental to the survival of patients after LTx. ${ }^{9-19}$ The most important finding of our study is that higher HLA mismatch level lowered the hazard of posttransplant mortality in children with a CF diagnosis, particularly in the youngest segment of this group. Although the small size of the pediatric cohort raises the question of whether this finding was related to chance, statistical analyses demonstrate a significant association adjusting for a variety of recipient, donor, and transplant characteristics, while also explicitly modeling age as a continuous moderator of the HLA mismatch effect.

Cellular immunity after solid organ transplantation involves direct stimulation by dendritic cells in the graft ${ }^{20}$ or activation of $\mathrm{T}$ cells through the migration of
TABLE 4. Univariate Cox survival analysis of children with cystic fibrosis $(n=489)$

\begin{tabular}{lcccc}
\hline \multicolumn{1}{c}{ Variable } & n & $\begin{array}{c}\text { Hazard } \\
\text { ratio }\end{array}$ & $\begin{array}{c}\text { Confidence } \\
\text { interval }\end{array}$ & $\begin{array}{c}\boldsymbol{P} \\
\text { value }\end{array}$ \\
\hline $\begin{array}{l}\text { Human leukocyte antigen } \\
\quad \text { mismatch }\end{array}$ & 363 & 0.87 & $0.77-0.99$ & .032 \\
$\quad$ Male recipient & 489 & 0.84 & $0.65-1.1$ & .19 \\
Male donor & 489 & 0.99 & $0.78-1.3$ & .96 \\
Race of recipient & 489 & & & \\
$\quad$ White & & ref & & \\
$\quad$ Black & & 1.1 & $0.44-2.6$ & .90 \\
$\quad$ Other & & 1.0 & $0.68-1.6$ & .89 \\
Race of donor & 489 & & & \\
$\quad$ White & & ref & & \\
$\quad$ Black & & 1.0 & $0.73-1.4$ & .90 \\
$\quad$ Other & & 0.91 & $0.65-1.3$ & .59 \\
Infection before lung transplant & 426 & 0.90 & $0.68-1.2$ & .45 \\
Age (y) & 489 & 1.0 & $1.0-1.1$ & .056 \\
Transplant year & 489 & 0.98 & $0.96-1.0$ & .097 \\
Creatinine (mg/dL) & 422 & 1.0 & $0.96-1.1$ & .30 \\
Body mass index & 474 & 1.0 & $0.99-1.1$ & .22 \\
Ischemic time (h) & 461 & 1.0 & $0.95-1.1$ & .43 \\
Forced expiratory volume & 424 & 1.0 & $0.99-1.0$ & .87 \\
$\quad$ in 1 s (\% predicted) & & & & \\
Forced vital capacity & 427 & 1.0 & $1.0-1.0$ & .27 \\
$\quad$ (\% predicted) & & & & \\
6-Minute walk test (100 ft) & 52 & 1.0 & $0.94-1.1$ & .58 \\
Lung allocation score & 208 & 0.99 & $0.97-1.0$ & .31 \\
\hline
\end{tabular}

ref, Reference category.

antigen-presenting cells to secondary lymphoid tissue (thoracic regional lymph nodes and spleen) ${ }^{20}$ or direct stimulation by dendritic cells in the graft. ${ }^{21} \mathrm{~T}$ cell receptors recognize the allogeneic HLAs on the donor cells via a

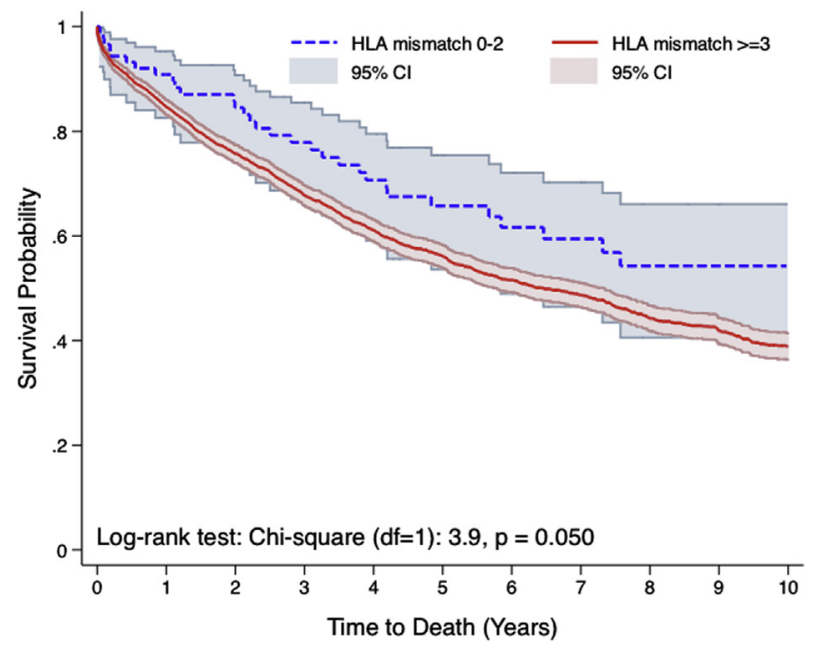

FIGURE 1. Kaplan-Meier survival functions of time to death for adults with cystic fibrosis according to human leukocyte antigen (HLA) mismatch $\geq 3$ versus 0 to $2(\mathrm{n}=2687)$. Log-rank test: $\chi^{2}(\mathrm{df}=1)$ : 3.9 ; $P=.050 . C I$, Confidence interval. 


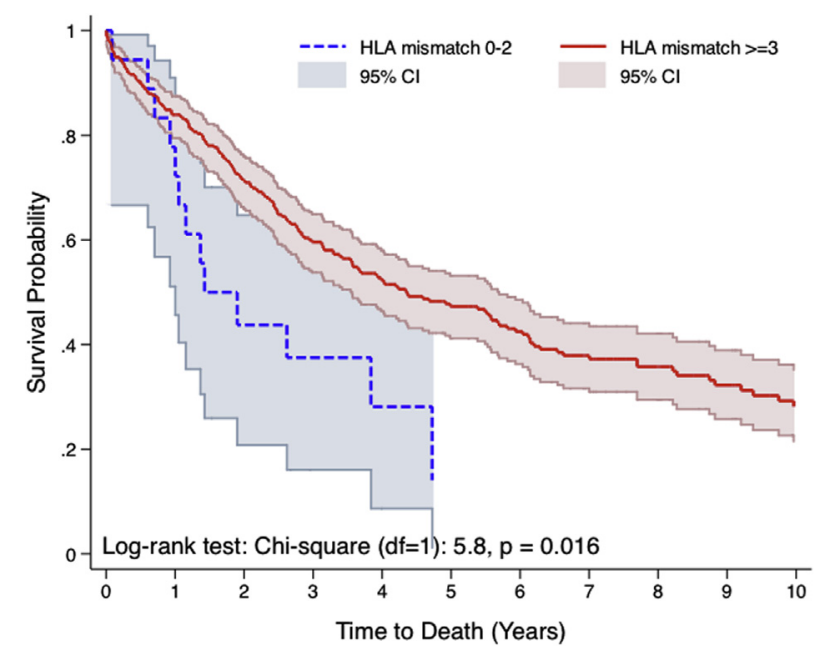

FIGURE 2. Kaplan-Meier survival functions of time to death for children with cystic fibrosis according to human leukocyte antigen (HLA) mismatch $\geq 3$ versus 0 to $2(\mathrm{n}=363), \log$-rank test: $\chi^{2}(\mathrm{df}=1): 5.8$; $P=.016 . C I$, Confidence interval.

direct pathway and peptide fragments of allogeneic HLA presented by recipient HLA molecules through an indirect pathway. ${ }^{20}$ The HLA class 1 genes are expressed on all nucleated cells, whereas HLA class 2 genes are expressed primarily on $\mathrm{B}$ and $\mathrm{T}$ cells, dendritic cells, monocytes, and other antigen-presenting cells. ${ }^{22,23}$

After LTx, recipients can develop a humoral response to the graft through antibody production against the donor HLAs. These antibodies bind to the allo-HLAs and activate the complement cascade with subsequent complement deposition, endothelial cell injury, and inflammatory injury. ${ }^{24}$ Antibody-mediated rejection (AMR) is increasing being recognized in LTx on a continuum that also includes latent, silent, and subclinical types, with concomitant circulating donor-specific anti-HLA antibodies (DSAs) and graft C4d deposition being a part of the diagnosis. ${ }^{24}$ LTx recipients can develop de novo DSAs and non-DSAs that are associated with AMR and can increase the incidence of both BOS and death. ${ }^{24-27}$ In a recent, single-center study of 44 LTx recipients, Lobo and colleagues ${ }^{28}$ reported that non-DSAs were detected more in their DSA group than the non-DSA group $(P=.0006)$, whereas AMR occurred more frequently in the non-DSA group compared with the group without non-DSAs (50\% [11 out of 22] vs $0 \%(0$ out of 22); $P=.002$ ). Of these 44 adult patients (age range, 17-67 years), 30 had CF with a significantly higher proportion being in the DSA group (12 out of 13 ). ${ }^{28}$ Thus, these investigators suggested that adult patients with CF may be at higher risk of DSA production and possibly AMR development after LTx.

TABLE 5. Multivariate Cox survival analysis of adults with cystic fibrosis

\begin{tabular}{|c|c|c|c|c|c|c|}
\hline \multirow[b]{2}{*}{ Variable } & \multicolumn{3}{|c|}{$\begin{array}{c}\text { Model } 1 \\
(\mathbf{n}=\mathbf{2 0 7 3}) \\
\end{array}$} & \multicolumn{3}{|c|}{$\begin{array}{c}\text { Model 2 } \\
(\mathbf{n}=1177) \\
\end{array}$} \\
\hline & HR & $\mathbf{9 5} \% \mathbf{C I}$ & $P$ value & HR & $95 \% \mathrm{CI}$ & $P$ value \\
\hline Human leukocyte antigen mismatch & 1.0 & $0.95-1.1$ & .68 & 1.1 & $0.97-1.2$ & .19 \\
\hline Male recipient & 1.1 & $0.92-1.2$ & .43 & 1.2 & $0.96-1.5$ & .11 \\
\hline Male donor & 0.94 & $0.81-1.1$ & .37 & 0.88 & $0.70-1.1$ & .27 \\
\hline \multicolumn{7}{|l|}{ Race of recipient } \\
\hline White & ref & & & ref & & \\
\hline Black & 0.91 & $0.51-1.6$ & .74 & 1.2 & $0.54-2.7$ & .64 \\
\hline Other & 0.72 & $0.46-1.1$ & .15 & 1.2 & $0.65-2.1$ & .60 \\
\hline \multicolumn{7}{|l|}{ Race of donor } \\
\hline White & ref & & & ref & & \\
\hline Black & 1.2 & $1.0-1.5$ & .029 & 1.4 & $1.0-1.8$ & .030 \\
\hline Other & 1.1 & $0.94-1.4$ & .19 & 1.1 & $0.84-1.5$ & .47 \\
\hline Infection before lung transplant & 1.1 & $0.99-1.3$ & .071 & 1.0 & $0.84-1.3$ & .67 \\
\hline Age $(y)$ & 0.98 & $0.97-0.98$ & $<.001$ & 0.97 & $0.96-0.98$ & $<.001$ \\
\hline Transplant year & 0.99 & $0.98-1.0$ & .15 & 0.99 & $0.93-1.0$ & .69 \\
\hline Creatinine (mg/dL) & 1.1 & $0.93-1.2$ & .39 & 1.1 & $0.95-1.3$ & .19 \\
\hline Body mass index & 1.0 & $0.98-1.0$ & .58 & 1.0 & $0.96-1.0$ & .96 \\
\hline Ischemic time (h) & 0.97 & $0.93-1.0$ & .15 & 0.99 & $0.93-1.1$ & .84 \\
\hline $\begin{array}{l}\text { Forced expiratory volume in } 1 \mathrm{~s} \\
(\% \text { predicted })\end{array}$ & 0.99 & $0.98-1.0$ & .027 & 0.99 & $0.98-1.0$ & .12 \\
\hline Forced vital capacity ( $\%$ predicted) & 1.0 & $1.0-1.0$ & .27 & 1.00 & $0.99-1.0$ & .69 \\
\hline Lung allocation score & & & & 1.0 & $1.0-1.0$ & .18 \\
\hline
\end{tabular}

HR, Hazard ratio; $C I$, confidence interval; ref, reference category. 
TABLE 6. Multivariate Cox survival analysis of children with cystic fibrosis

\begin{tabular}{|c|c|c|c|c|c|c|}
\hline \multirow[b]{2}{*}{ Variable } & \multicolumn{3}{|c|}{$\begin{array}{c}\text { Model } 1 \\
(\mathbf{n}=\mathbf{2 5 7})\end{array}$} & \multicolumn{3}{|c|}{$\begin{array}{c}\text { Model } 2 \\
(n=116)\end{array}$} \\
\hline & HR & $\mathbf{9 5} \% \mathrm{CI}$ & $P$ value & HR & $\mathbf{9 5} \% \mathrm{CI}$ & $P$ value \\
\hline Human leukocyte antigen mismatch & 0.87 & $0.73-1.0$ & .093 & 0.71 & $0.54-0.93$ & .015 \\
\hline Male recipient & 1.1 & $0.73-1.6$ & .75 & 1.3 & $0.64-2.8$ & .44 \\
\hline Male donor & 0.75 & $0.53-1.1$ & .11 & 1.2 & $0.59-2.5$ & .61 \\
\hline \multicolumn{7}{|l|}{ Race of recipient } \\
\hline White & ref & & & ref & & \\
\hline Black & 3.3 & $1.1-9.9$ & .035 & 2.4 & $0.29-20$ & .41 \\
\hline Other & 1.2 & $0.61-2.5$ & .55 & 0.71 & $0.27-1.9$ & .50 \\
\hline \multicolumn{7}{|l|}{ Race of donor } \\
\hline White & ref & & & ref & & \\
\hline Black & 0.98 & $0.58-1.7$ & .93 & 0.74 & $0.29-1.8$ & .52 \\
\hline Other & 0.44 & $0.25-0.77$ & .005 & 0.41 & $0.16-1.0$ & .057 \\
\hline Infection before transplant & 0.94 & $0.65-1.4$ & .77 & 1.6 & $0.82-3.0$ & .18 \\
\hline Age (y) & 1.1 & $1.0-1.2$ & .011 & 0.94 & $0.82-1.1$ & .42 \\
\hline Transplant year & 1.0 & $0.96-1.0$ & .99 & 1.1 & $0.87-1.3$ & .59 \\
\hline Creatinine (mg/dL) & 1.1 & $0.91-1.4$ & .27 & 1.2 & $0.24-6.6$ & .79 \\
\hline Body mass index & 0.98 & $0.92-1.0$ & .43 & 1.1 & $0.94-1.3$ & .25 \\
\hline Ischemic time $(\mathrm{h})$ & 1.0 & $0.92-1.2$ & .59 & 1.0 & $0.85-1.3$ & .75 \\
\hline $\begin{array}{l}\text { Forced expiratory volume in } 1 \mathrm{~s} \\
\quad(\% \text { predicted })\end{array}$ & 1.0 & $0.98-1.0$ & .87 & 0.97 & $0.94-1.0$ & .15 \\
\hline Forced vital capacity ( $\%$ predicted) & 1.0 & $0.98-1.0$ & .94 & 1.0 & $0.99-1.1$ & .11 \\
\hline Lung allocation score & & & & 1.0 & $0.98-1.0$ & .85 \\
\hline
\end{tabular}

Increased HLA mismatching being protective and reducing the mortality HR in children with CF after LTx is counterintuitive to current practice. The data regarding humoral immunity in children after LTx are even more limited than what exists in the adult population. Nevertheless, HLA disparities between adult and pediatric recipients as seen in our analysis is consistent with the evolving medical literature in hematopoietic stem cell transplantation. ${ }^{29-31}$ With a retrospective study, we cannot determine causality or mechanisms involved, so future research is needed to explore the differences in humoral immunity in adult and pediatric patients with $\mathrm{CF}$.

Several investigators have identified that B lymphocytes transcribe the CFTR gene and exhibit CF-defective cAMP-regulated chloride current. ${ }^{32-45}$ With CFTR dysfunction being the defect in $\mathrm{CF}$, an alteration in $\mathrm{B}$ lymphocyte function may exist in $\mathrm{CF}$, particularly earlier in the disease course when younger patients have more naïve $\mathrm{B}$ cells. In support of this theory, patients with $\mathrm{CF}$ are known to be poor serologic responders to various vaccines, ${ }^{46-48}$ suggesting potential $\mathrm{B}$ cell dysfunction. Moreover, Pseudomonas aeruginosa stimulates B lymphocyte proliferation. ${ }^{49,50}$ Therefore, this pathogen commonly seen in CF may also be playing a role in this immunologic process. Another potential factor is permissive HLA mismatching, which is an evolving concept in allogeneic hematopoietic cell transplantation where 8 of 8 HLA allele-level matches (HLA-A, -B, -C, and -DRB1) are preferred. Permissive HLA mismatch allows transplantation of single locus mismatches where the locus may not be clinically relevant. ${ }^{51,52}$ Therefore, certain HLA mismatches may not necessarily be significant at a younger age, further suggesting differences in immune response based on age and, potentially, a higher prevalence of immune tolerance in younger LTx recipients versus older patients. Evidence supporting this theory of a more tolerant immune system in children is slowly expanding in the medical literature. . $^{53-56}$

Our study is limited by the retrospective collection of data from a large database that could potentially not include confounding variables with further potential risk for data entry errors and missing data points. Despite its limitations, our study draws results from a large, multiinstitutional registry database of transplant recipients and thus reduces potential biases observed in single-institution observational studies.

\section{CONCLUSIONS}

We found that greater HLA mismatching reduced the risk for death among children with CF who underwent LTx, while there was no impact on survival among adults with CF. With these observed differences in HLA matching between adult and pediatric patients with $\mathrm{CF}$, further research is needed to define humoral immunity in this LTx population in which age-related disparities exists. 
TABLE 7. Multivariate Cox survival analysis of children and adults with cystic fibrosis, interacting human leukocyte antigen (HLA) mismatch with age at lung transplantation

\begin{tabular}{|c|c|c|c|c|c|c|}
\hline \multirow[b]{2}{*}{ Variable } & \multicolumn{3}{|c|}{$\begin{array}{c}\text { Model 3 } \\
(\mathbf{n}=\mathbf{3 0 5 0}) \\
\end{array}$} & \multicolumn{3}{|c|}{$\begin{array}{c}\text { Model } 4 \\
(n=2330)\end{array}$} \\
\hline & HR & $\mathbf{9 5} \% \mathrm{CI}$ & $P$ value & HR & $\mathbf{9 5} \% \mathrm{CI}$ & $P$ value \\
\hline HLA mismatch & 0.87 & $0.77-0.99$ & .030 & 0.85 & $0.73-0.99$ & .044 \\
\hline Age $(y / 10)$ & 0.63 & $0.50-0.80$ & $<.001$ & 0.60 & $0.44-0.80$ & $<.001$ \\
\hline Age $\times$ HLA mismatch & 1.1 & $1.0-1.1$ & .023 & 1.1 & $1.0-1.1$ & .038 \\
\hline Male recipient & & & & 1.0 & $0.91-1.2$ & .59 \\
\hline Male donor & & & & 0.93 & $0.82-1.1$ & .29 \\
\hline \multicolumn{7}{|l|}{ Race of recipient } \\
\hline White & & & & ref & & \\
\hline Black & & & & 1.0 & $0.61-1.7$ & .97 \\
\hline Other & & & & 0.77 & $0.53-1.1$ & .16 \\
\hline \multicolumn{7}{|l|}{ Race of donor } \\
\hline White & & & & ref & & \\
\hline Black & & & & 1.2 & $1.0-1.4$ & .040 \\
\hline Other & & & & 1.0 & $0.87-1.2$ & .71 \\
\hline Infection before lung transplant & & & & 1.1 & $0.97-1.2$ & .14 \\
\hline Transplant year & & & & 0.99 & $0.98-1.0$ & .35 \\
\hline Creatinine $(\mathrm{mg} / \mathrm{dL})$ & & & & 1.1 & $0.96-1.2$ & .22 \\
\hline Body mass index & & & & 1.0 & $0.99-1.0$ & .44 \\
\hline Ischemic time (h) & & & & 0.98 & $0.94-1.0$ & .20 \\
\hline Forced expiratory volume in $1 \mathrm{~s}(\%$ predicted $)$ & & & & 0.99 & $0.99-1.0$ & .043 \\
\hline Forced vital capacity ( $\%$ predicted $)$ & & & & 1.0 & $0.98-1.0$ & .24 \\
\hline
\end{tabular}

\section{Conflict of Interest Statement}

Authors have nothing to disclose with regard to commercial support.

The authors thank Dmitry Tumin for providing statistical expertise in the data analysis.

\section{References}

1. Yusen RD, Edwards LB, Kucheryavaya AY, Benden C, Dipchand AI, Dobbels F, et al. The registry of the International Society for Heart and Lung Transplantation: thirty-first adult lung and heart-lung transplant report-2014; focus theme: retransplantation. J Heart Lung Transplant. 2014;33:1009-24.

2. Benden C, Goldfarb SB, Edwards LB, Kucheryavaya AY, Christie JD, Dipchand AI, et al. The registry of the International Society for Heart and Lung Transplantation: seventeenth official pediatric lung and heart-lung transplantation report-2014; focus theme: retransplantation. J Heart Lung Transplant. 2014;33:1025-33.

3. Thabut G, Christie JD, Mal H, Fournier M, Brugière O, Leseche G, et al. Survival benefit of lung transplant for cystic fibrosis since lung allocation score implementation. Am J Respir Crit Care Med. 2013;187:1335-40.

4. Liou TG, Adler FR, Cox DR, Cahill BC. Lung transplantation and survival in children with cystic fibrosis. $N$ Engl J Med. 2007;357:2143-52. Erratum in: N Engl J Med. 2008;359:e6.

5. Sweet SC, Aurora P, Benden C, Wong JY, Goldfarb SB, Elidemir O, et al. Lung transplantation and survival in children with cystic fibrosis: solid statisticsflawed interpretation. Pediatr Transplant. 2008;12:129-36.

6. Aurora P, Carby M, Sweet S. Selection of cystic fibrosis patients for lung transplantation. Curr Opin Pulm Med. 2008;14:589-94.

7. Hayes D Jr, McCoy KS, Whitson BA, Mansour HM, Tobias JD. High-risk age window for mortality in children with cystic fibrosis after lung transplantation. Pediatr Transplant. 2015;19:206-10.

8. United Network for Organ Sharing/Organ Procurement and Transplantation Network Standard Transplant Analysis and Research Database. http://optn. transplant.hrsa.gov/data/about/OPTNDatabase.asp. Accessed September 6, 2013.
9. Smith MA, Sundaresan S, Mohanakumar T, Trulock EP, Lynch JP, Phelan DL, et al. Effect of development of antibodies to HLA and cytomegalovirus mismatch on lung transplantation survival and development of bronchiolitis obliterans syndrome. J Thorac Cardiovasc Surg. 1998;116:812-20.

10. Brugière O, Thabut G, Suberbielle C, Reynaud-Gaubert M, Thomas P, Pison C, et al. Relative impact of human leukocyte antigen mismatching and graft ischemic time after lung transplantation. J Heart Lung Transplant. 2008;27:628-34.

11. Wisser W, Wekerle T, Zlabinger G, Senbaclavaci O, Zuckermann A, Klepetko W, et al. Influence of human leukocyte antigen matching on long-term outcome after lung transplantation. J Heart Lung Transplant. 1996;15:1209-16.

12. Sundaresan S, Mohanakumar T, Smith MA, Trulock EP, Lynch J, Phelan D, et al. HLA-A locus mismatches and development of antibodies to HLA after lung transplantation correlate with the development of bronchiolitis obliterans syndrome. Transplantation. 1998;65:648-53.

13. Schulman LL, Weinberg AD, McGregor C, Galantowicz ME, Suciu-Foca NM, Itescu S. Mismatches at the HLA-DR and HLA-B loci are risk factors for acute rejection after lung transplantation. Am J Respir Crit Care Med. 1998;157(6 Pt $1): 1833-7$.

14. van den Berg JW, Hepkema BG, Geertsma A, Koëter GH, Postma DS, de Boer WJ, et al. Long-term outcome of lung transplantation is predicted by the number of HLA-DR mismatches. Transplantation. 2001;71:368-73.

15. Love RB, Meyer KC, Devito-Haynes LD, Ulschmid S, Leverson GE, Van Der Bij W, et al. Effect of HLA-DR mismatch on lung transplant outcome. J Heart Lung Transplant. 2001;20:177.

16. Chalermskulrat W, Neuringer IP, Schmitz JL, Catellier DJ, Gurka MJ, Randell SH, et al. Human leukocyte antigen mismatches predispose to the severity of bronchiolitis obliterans syndrome after lung transplantation. Chest. 2003; 123:1825-31.

17. Quantz MA, Bennett LE, Meyer DM, Novick RJ. Does human leukocyte antigen matching influence the outcome of lung transplantation? An analysis of 3,549 lung transplantations. J Heart Lung Transplant. 2000;19:473-9.

18. Opelz G, Süsal C, Ruhenstroth A, Döhler B. Impact of HLA compatibility on lung transplant survival and evidence for an HLA restriction phenomenon: a collaborative transplant study report. Transplantation. 2010;90:912-7.

19. Peltz M, Edwards LB, Jessen ME, Torres F, Meyer DM. HLA mismatches influence lung transplant recipient survival, bronchiolitis obliterans and rejection: implications for donor lung allocation. J Heart Lung Transplant. 2011;30:426-34. 
20. Gelman AE, Li W, Richardson SB, Zinselmeyer BH, Lai J, Okazaki M, et al. Cutting edge: acute lung allograft rejection is independent of secondary lymphoid organs. J Immunol. 2009;182:3969-73.

21. Larsen CP, Morris PJ, Austyn JM. Donor dendritic leukocytes migrate from cardiac allografts into recipients' spleens. Transplant Proc. 1990;22:1943-4.

22. Klein J, Sato A. The HLA system. First of two parts. N Engl J Med. 2000;343: 702-9.

23. Klein J, Sato A. The HLA system. Second of two parts. N Engl J Med. 2000;343: 782-6. Erratum in: N Engl J Med. 2000;343:1504.

24. McManigle W, Pavlisko EN, Martinu T. Acute cellular and antibody-mediated allograft rejection. Semin Respir Crit Care Med. 2013;34:320-35.

25. Takemoto SK, Zeevi A, Feng S, Colvin RB, Jordan S, Kobashigawa J, et al. National conference to assess antibody-mediated rejection in solid organ transplantation. Am J Transplant. 2004;4:1033-41.

26. Girnita AL, McCurry KR, Iacono AT, Duquesnoy R, Corcoran TE, Awad M, et al. HLA-specific antibodies are associated with high-grade and persistentrecurrent lung allograft acute rejection. J Heart Lung Transplant. 2004;23: $1135-41$

27. Girnita AL, Duquesnoy R, Yousem SA, Iacono AT, Corcoran TE, Buzoianu M, et al. HLA-specific antibodies are risk factors for lymphocytic bronchiolitis and chronic lung allograft dysfunction. Am J Transplant. 2005;5:131-8.

28. Lobo LJ, Aris RM, Schmitz J, Neuringer IP. Donor-specific antibodies are associated with antibody-mediated rejection, acute cellular rejection, bronchiolitis obliterans syndrome, and cystic fibrosis after lung transplantation. J Heart Lung Transplant. 2013;32:70-7.

29. Führer M, Durner J, Brünnler G, Götte H, Deppner C, Bender-Götze C, et al. HLA association is different in children and adults with severe acquired aplastic anemia. Pediatr Blood Cancer. 2007:48:186-91.

30. Atsuta Y, Kanda J, Takanashi M, Morishima Y, Taniguchi S, Takahashi S, et al. Different effects of HLA disparity on transplant outcomes after single-unit cord blood transplantation between pediatric and adult patients with leukemia. Haematologica. 2013;98:814-22.

31. Kanda J. Effect of HLA mismatch on acute graft-versus-host disease. Int J Hematol. 2013;98:300-8.

32. Johansson J, Vezzalini M, Verzè G, Caldrer S, Bolognin S, Buffelli M, et al. Detection of CFTR protein in human leukocytes by flow cytometry. Cytometry A. 2014;85:611-20.

33. McDonald TV, Nghiem PT, Gardner P, Martens CL. Human lymphocytes transcribe the cystic fibrosis transmembrane conductance regulator gene and exhibit CF-defective cAMP-regulated chloride current. J Biol Chem. 1992;267:3242-8.

34. Krauss RD, Bubien JK, Drumm ML, Zheng T, Peiper SC, Collins FS, et al. Transfection of wild-type CFTR into cystic fibrosis lymphocytes restores chloride conductance at G1 of the cell cycle. EMBO J. 1992;11:875-83.

35. Krauss RD, Berta G, Rado TA, Bubien JK. Antisense oligonucleotides to CFTR confer a cystic fibrosis phenotype on B lymphocytes. Am J Physiol. 1992;263(6 Pt 1):C1147-51.

36. Will K, Reiss J, Dean M, Schlösser M, Slomski R, Schmidtke J, et al. CFTR transcripts are undetectable in lymphocytes and respiratory epithelial cells of a CF patient homozygous for the nonsense mutation R553X. J Med Genet. 1993; 30:833-7.

37. Will K, Dörk T, Stuhrmann M, von der Hardt H, Ellemunter H, Tümmler B, et al. Transcript analysis of CFTR nonsense mutations in lymphocytes and nasal epithelial cells from cystic fibrosis patients. Hum Mutat. 1995;5:210-20.

38. Dong YJ, Chao AC, Kouyama K, Hsu YP, Bocian RC, Moss RB, et al. Activation of CFTR chloride current by nitric oxide in human T lymphocytes. EMBO J. 1995; 14:2700-7.

39. Romey MC, Tuffery S, Desgeorges M, Bienvenu T, Demaille J, Claustres M. Transcript analysis of CFTR frameshift mutations in lymphocytes using the reverse transcription-polymerase chain reaction technique and the protein truncation test. Hum Genet. 1996:98:328-32.

40. Moss RB, Bocian RC, Hsu YP, Dong YJ, Kemna M, Wei T, et al. Reduced IL-10 secretion by CD4+ T lymphocytes expressing mutant cystic fibrosis transmembrane conductance regulator (CFTR). Clin Exp Immunol. 1996; 106:374-88

41. Lepple-Wienhues A, Wieland U, Laun T, Heil L, Stern M, Lang F. A src-like kinase activates outwardly rectifying chloride channels in CFTR-defective lymphocytes. FASEB J. 2001;15:927-31.

42. Bubien JK. CFTR may play a role in regulated secretion by lymphocytes: a new hypothesis for the pathophysiology of cystic fibrosis. Pflugers Arch. 2001 443(Suppl 1):S36-9.

43. Mueller C, Braag SA, Keeler A, Hodges C, Drumm M, Flotte TR. Lack of cystic fibrosis transmembrane conductance regulator in CD3+ lymphocytes leads to aberrant cytokine secretion and hyperinflammatory adaptive immune responses. Am J Respir Cell Mol Biol. 2011;44:922-9.

44. Moss RB, Hsu YP, Olds L. Cytokine dysregulation in activated cystic fibrosis (CF) peripheral lymphocytes. Clin Exp Immunol. 2000;120: $518-25$.

45. Tang XX, Fok KL, Chen H, Chan KS, Tsang LL, Rowlands DK, et al. Lymphocyte CFTR promotes epithelial bicarbonate secretion for bacterial killing. J Cell Physiol. 2012;227:3887-94.

46. Galar A, Engelson BA, Kubiak DW, Licona JH, Boukedes S, Goldberg HJ, et al Serologic response to hepatitis B vaccination among lung transplantation candidates. Transplantation. 2014;98:676-9.

47. Browning MJ, Lim MT, Kenia P, Whittle M, Doffinger R, BarcenasMorales G, et al. Pneumococcal polysaccharide vaccine responses are impaired in a subgroup of children with cystic fibrosis. J Cyst Fibros 2014;13:632-8.

48. Launay O, Boelle PY, Krivine A, Grenet D, Boussaud V, Rémus N, et al. Factor associated with humoral immune response to pandemic A/H1N1(v) 2009 influenza vaccine in cystic fibrosis. Vaccine. 2014;32:4515-21.

49. Mody CH, Buser DE, Syme RM, Woods DE. Pseudomonas aeruginosa exoenzyme S induces proliferation of human T lymphocytes. Infect Immun. 1995;63: 1800-5.

50. Barclay NG, Spurrell JC, Bruno TF, Storey DG, Woods DE, Mody CH. Pseudomonas aeruginosa exoenzyme $\mathrm{S}$ stimulates murine lymphocyte proliferation in vitro. Infect Immun. 1999;67:4613-9.

51. Szabolcs P. Permissive mismatches for blood and marrow transplantation. Lancet Oncol. 2012;13:323-4.

52. Bacigalupo A. A closer look at permissive HLA mismatch. Blood. 2013;122 3555-6.

53. Shaw AC, Goldstein DR, Montgomery RR. Age-dependent dysregulation of innate immunity. Nat Rev Immunol. 2013;13:875-87.

54. Heinze A, Elze MC, Kloess S, Ciocarlie O, Königs C, Betz S, et al. Age-matched dendritic cell subpopulations reference values in childhood. Scand J Immunol. 2013;77:213-20

55. Kollmann TR, Levy O, Montgomery RR, Goriely S. Innate immune function by Toll-like receptors: distinct responses in newborns and the elderly. Immunity. 2012;37:771-83

56. Gough EK, Moodie EE, Prendergast AJ, Johnson SM, Humphrey JH, Stoltzfus RJ, et al. The impact of antibiotics on growth in children in low and middle income countries: systematic review and meta-analysis of randomised controlled trials. BMJ. 2014;348:g2267.

Key Words: cystic fibrosis, human leukocyte antigen mismatch, lung transplantation, survival 
TABLE E1. Number of patients at risk, by human leukocyte antigen (HLA) mismatch level and year since transplant among a cohort of adults with cystic fibrosis who received a lung transplant

\begin{tabular}{lcc}
\hline & \multicolumn{2}{c}{ Patients at risk } \\
\cline { 2 - 3 } Year since transplant & HLA 0-2 & HLA $\geq \mathbf{3}$ \\
\hline 0 & 91 & 2581 \\
1 & 74 & 1978 \\
2 & 66 & 1591 \\
3 & 55 & 1276 \\
4 & 49 & 1035 \\
5 & 35 & 852 \\
6 & 30 & 693 \\
7 & 26 & 578 \\
8 & 20 & 466 \\
9 & 17 & 383 \\
10 & 14 & 309 \\
\hline HLA, Human leukocyte antigen & &
\end{tabular}

HLA, Human leukocyte antigen.

TABLE E2. Number of patients at risk, by human leukocyte antigen (HLA) mismatch level and year since transplant among a cohort of children with cystic fibrosis who received a lung transplant

\begin{tabular}{lcc}
\hline & \multicolumn{2}{c}{ Patients at risk } \\
\cline { 2 - 3 } Year since transplant & HLA 0-2 & HLA $\geq \mathbf{3}$ \\
\hline 0 & 0 & 21 \\
1 & 1 & 14 \\
2 & 2 & 7 \\
3 & 3 & 4 \\
4 & 4 & 2 \\
5 & 5 & 1 \\
6 & 6 & 1 \\
7 & 7 & 1 \\
8 & 8 & 1 \\
9 & 9 & 1 \\
10 & 10 & 1 \\
\hline
\end{tabular}

HLA, Human leukocyte antigen. 